\title{
IgG4-Related Disease: A Constellation of Abdominal Manifestations
}

\author{
Kapil Wattamwar ${ }^{1 *}$, Justin Holder ${ }^{1}$ \\ 1. Department of Radiology, Montefiore Medical Center, Bronx, NY, USA \\ * Correspondence: Kapil Wattamwar, MD, Department of Radiology, Montefiore Medical Center, 111 East 210th Street, Bronx, NY \\ 10467, USA \\ (入kwattamw@montefiore.org)
}

Radiology Case. 2022 Feb; 16(2):12-20 $\quad$ :: $\quad$ DOI: $10.3941 /$ jrcr.v16i2.4266

\begin{abstract}
IgG4-related disease is an autoimmune condition that results in inflammation and fibrosis throughout multiple organ systems. This disease is rare; however, it can mimic many more prevalent conditions clinically and thus should be included in their differential diagnoses. Although autoimmune pancreatitis is the most common abdominal manifestation, the disease can afflict the hepatobiliary, vascular and renal systems as well. We present a case of a 78year-old male with symptoms of chronic fatigue and weight loss. Imaging was performed with the expectation of revealing a malignancy, although the features of IgG4-related disease involving multiple organs were detected instead. Serology confirmed the diagnosis. It is imperative to diagnose IgG4related disease early as it has a different treatment and favorable prognosis compared to many malignancies.
\end{abstract}

\section{CASE REPORT}

\section{CASE REPORT}

A 78-year-old male presented to his primary care physician's office with complaints of chronic fatigue, frequent bowel movements and an unintentional 30-pound weight loss over the course of 2 years. He denied fevers, chills or night sweats and did not experience vomiting, hematochezia or abdominal pain. There was no history of liver or pancreatic disease or known chemical toxin or radiation exposure. He was a former smoker with ongoing moderate alcohol use and past medical history notable for coronary artery disease with placement of multiple coronary stents, type 2 diabetes mellitus and benign prostatic hypertrophy. Surgical history was noncontributory. On physical exam, the patient had no jaundice or scleral icterus. The abdomen was soft and nontender. There was no palpable lymphadenopathy. Serology demonstrated elevated LFT's (liver function tests) with AST, ALT and alkaline phosphatase levels of 89 (0-35), 54 (0-35) and 298 (36150) U/L, respectively, as well as elevated total and direct bilirubin of $1.4(0.3-1.2)$ and $0.9(0.0-0.3) \mathrm{mg} / \mathrm{dL}$, respectively. Albumin was $3.0(3.5-5.4) \mathrm{g} / \mathrm{dL}$ while total protein was 8.3 (6.07.8) $\mathrm{g} / \mathrm{dL}$. The patient also had a hemoglobin of 8.7 (14-17) $\mathrm{g} / \mathrm{dL}$ with mean corpuscular volume of 108 (80-100) fL, with a previously unremarkable complete blood count last obtained 4 years prior. There was a normal leukocyte differential and no electrolyte abnormalities.

The patient next underwent contrast enhanced computed tomography (CT) of the abdomen and pelvis, which revealed infiltrative soft tissue in the region of the biliary hilum with moderate to severe upstream intrahepatic biliary dilatation, suggestive of a stricture (Figure 1). There was heterogenous 
enhancement throughout the liver, with a focal hypoenhancing region noted in the left hepatic lobe (Figure 2). It was unclear if this focal lesion represented a hepatic mass, pseudotumor or inflamed parenchyma. The pancreas had lost its normal lobulated architecture and its parenchyma was diffusely enhancing with a surrounding rind of soft tissue (Figure 1). These findings were suggestive of autoimmune pancreatitis. Soft tissue also surrounded the proximal aspects of the superior and inferior mesenteric arteries (Figures 3, 4). Asymmetric prominence of the seminal vesicle was also noted, thought to be due to an underlying prostatic lesion or an infectious or inflammatory prostatitis.

IgG4-related disease was suggested based on the CT findings, and a contrast enhanced magnetic resonance imaging (MRI) with magnetic resonance cholangiopancreatography MRCP was recommended in conjunction with serum IgG levels.

The MRI revealed soft tissue encased the proximal common bile duct (CBD) and biliary hilum, resulting in a $4 \mathrm{~cm}$ long stricture, with increased upstream intrahepatic biliary dilatation (Figures 5, 6). The hepatic parenchyma demonstrated diffuse heterogeneous enhancement, without a focal mass or pseudotumor, consistent with inflammatory changes. The pancreas demonstrated parenchymal $\mathrm{T} 2$ hyperintensity and $\mathrm{T} 1$ hypointensity with diffuse enhancement, including an enhancing peripheral soft tissue rind, again consistent with autoimmune pancreatitis (Figure 7). The kidneys also demonstrated multifocal regions of abnormal enhancement and restricted diffusion (Figure 9, 10). Persistent enhancing soft tissue surrounding the SMA and IMA was again noted (Figure $11,12)$

IgG level was elevated at $3760 \mathrm{mg} / \mathrm{dL}$, and the $\mathrm{IgG} 4$ subclass was increased at $506 \mathrm{mg} / \mathrm{dL}$ (normal value 4.0-86.0 $\mathrm{mg} / \mathrm{dL}$ ). There was no monoclonal protein on SPEP. A hepatitis viral panel was normal. Antineutrophil cytoplasmic antibody (ANCA) was negative.

After a diagnosis of IgG-4 related disease was made, steroid therapy was strongly considered, as is known to be first line treatment. However in the setting of poorly controlled diabetes with repeatedly documented severe hyperglycemia and in the midst of the early COVID-19 pandemic period, it was decided to instead monitor the patient's laboratory values while following up symptomatology and imaging as needed. Additionally, the patient was soon after diagnosed with myelodysplastic syndrome, which impeded treatment of IgG-4 RD with immunosuppressive medications. Liver function tests and symptoms peaked at the time of initial diagnosis and thereafter improved until transaminases reached normal levels 7 months later without steroid therapy. On follow-up MRI 10 months after initial diagnosis, slightly worsened extent of restricted diffusion was noted in the kidneys. Other findings remained stable from initial imaging, including long intrahepatic strictures with adjacent parenchymal inflammation, autoimmune pancreatitis, and vasculitis.

\section{DISCUSSION}

\section{Etiology \& Demographics:}

IgG4-related autoimmune disease is a rare immunemediated systemic condition characterized by focal or diffuse inflammation with associated fibrosis that contains abundant IgG4 plasmacytes. The disease was first identified in 2003, when patients with autoimmune pancreatitis (AIP) were noted to have extra-pancreatic manifestations.[1] While pancreas is the most commonly affected organ, many abdominopelvic organ systems may be involved.

There are two types of AIP. The first is associated with IgG4-related disease and is most commonly found in men aged 59-89. The prevalence is estimated to be $2-11 \%$ of patients with chronic pancreatitis.[1] Type 2 AIP is not associated with elevated serum IgG4 levels and is typically found in younger patients.

\section{Clinical \& Imaging Findings:}

AIP manifests on imaging as diffuse pancreatic enlargement with loss of parenchymal lobulations and a surrounding rim of fibrotic and inflammatory infiltrate. The parenchyma is hypodense on arterial phase CT, and hyperattenuating on delayed contrast phases. The peripancreatic rim is typically hypodense. The pancreas typically appears T2 hyper/T1 hypointense on MRI, hypointense on arterial phase and hyperintense on delayed venous phase contrast-enhanced imaging. The capsule is T2/T1 hypointense, with delayed hyperenhancement. The main pancreatic duct is often narrowed, which is best visualized on MRCP images. Focal AIP may simulate a pancreatic mass, although visualization of the pancreatic duct coursing through the lesion helps confirm the former etiology.[1]

The biliary system is next most commonly involved after the pancreas. Hepatobiliary manifestations of IgG4-related disease include sclerosing cholangitis, hepatopathy and inflammatory hepatic pseudotumor. Sclerosing cholangitis is seen in up to $88 \%$ of patients with type 1 AIP.[1] The involved biliary segments demonstrated thickened, enhancing walls with luminal narrowing and stenosis, with upstream dilatation. These strictures are often solitary and involve a continuous long ductal segment, frequently involving the common bile duct, with symmetric periductal soft tissue that may also be seen in nonstenotic regions. IgG4-related sclerosing cholangitis is more commonly associated with allergic conditions such as sinusitis, bronchial asthma and drug allergies. [2]

There are two widely used sets of diagnostic criteria for IgG-4-related sclerosing cholangitis, neither of which necessitates histology. The Japanese system stratifies the likelihood of the disease, stating that a combination of biliary tract segmental narrowing with ductal wall thickening on imaging and either autoimmune pancreatitis or retroperitoneal fibrosis constitutes "definite" diagnostic criteria, while the biliary imaging features coexisting with serum $\operatorname{IgG} 4 \geq 135$ $\mathrm{mg} / \mathrm{dL}$ meets the "possible" diagnostic category. The demonstration of steroid therapy response with the biliary imaging and serology findings constitutes "probable" diagnosis. The HISORt (histologic findings, characteristic imaging features, positive serologic findings, other organ 
involvement) system does not arrange categories into likelihood, but rather suggests that diagnosis can be made if imaging features of sclerosing cholangitis and autoimmune pancreatitis are present with elevated IgG4 levels.[3]

The retroperitoneal manifestations of IgG4-related disease include aortitis and retroperitoneal fibrosis. Periaortic lesions include enhancing nonstenotic mural thickening, with or without surrounding inflammation. These may result in arterial dilatation or inflammatory aortic aneurysms. [4] Fibrosis may manifest as infiltrative periaortic or periarterial soft tissue, a focal plaque-like mass or a periureteral mass. CT demonstrates soft tissue encasing the aorta or its branches, while the MRI signal intensity varies based on disease stage and inflammation activity. The fibrosis demonstrates low-intermediate T1 signal intensity with $\mathrm{T} 2$ hyperintensity and enhancement seen in the early active stage, and T2 hypointensity and hypoenhancement in the later fibrous stage.[5]

Renal involvement has been described in $30 \%$ of patients with AIP, and includes discrete rounded or wedge-shaped parenchymal lesions, perinephric soft tissue rind, or diffuse renal enlargement. The focal lesions may be hypodense on pre contrast or corticomedullary phase CT imaging, and demonstrates gradual delayed enhancement. The MRI contrast enhancement is similar, and the lesions demonstrate restricted diffusion and $\mathrm{T} 2$ hyperintensity.[6]

Biopsy is often utilized in diagnosing IgG4-related disease due to its overlapping imaging features with many other conditions. For example, endoscopic tissue sampling of the bile ducts may be performed in cases of sclerosing cholangitis. In this scenario, IgG4-related disease demonstrates transmural infiltration of the bile ducts that is rich in IgG4-positive plasma cells and interstitial fibrosis, with normal epithelium. Primary sclerosing cholangitis, on the other hand, typically has distorted epithelium and few IgG4-positive plasma cells [3]. Percutaneous biopsy has also been obtained in the liver to distinguish hepatic masses and inflammatory pseudotumor, and in the retroperitoneum to exclude retroperitoneal fibrosis. The hallmark of IgG4-related disease in these cases, as mentioned previously, is inflammation with fibrosis and abundant $\mathrm{IgG} 4$ plasmocytes [1].

The role of 18FDG PET/CT in diagnosis of IgG4-relatd diseases is controversial. The inflammatory substance shows uptake on FDG PET scans, which is nonspecific if a solitary organ is involved, for example in the pancreas, retroperitoneum or in vessel walls [1]. If multiorgan uptake is present in the appropriate clinical setting, though, it may suggest IgG4-related disease. PET/CT may also be helpful in targeting tissue for biopsy, and for monitoring treatment response [3].

IgG4-related disease can affect most abdominopelvic organs, with imaging features typically being manifestations of plasma cell infiltration and associated fibrosis. Imaging is useful in the initial diagnosis and treatment response assessment, and CT, MRI and MRCP are all complimentary in assessing the varied organ involvement.

\section{Treatment \& Prognosis:}

Early recognition and treatment of $\mathrm{IgG}$-4-related disease are crucial because the disease is indolent can progress from its initial treatment-responsive inflammatory stage to a poorly responsive fibrotic disease that causes damage to multiple organ systems.

Glucocorticoids are the first-line agent to treat active, untreated IgG4-related disease [2]. Patients usually respond within one month of initiation. IgG4-related sclerosing cholangitis often responds favorably to corticosteroids and $\mathrm{MRCP}$ is used in assessing treatment response [1]. Retroperitoneal fibrosis can also be followed on MRI to assess response to therapy [5]. Pancreatic function and morphology can be followed in the setting of autoimmune pancreatitis.

After a significant response is achieved in the affected organ system, the dose of glucocorticoids is tapered [3]. Patients may experience flares during or after steroid tapers, thus necessitating additional therapy such as rituximab [3]. Rituximab may also be used in cases where a glucocorticoidsparing approach may benefit the patient, such as in the setting of diabetes, osteoporosis, hypertension, and obesity. There is no consensus as to whether patients with IgG4-related disease should receive maintenance therapy. Patients who relapse while off treatment after successful induction of remission are treated with glucocorticoids.

The natural history of IgG4-related disease (IgG4-RD) has not been well characterized in the literature. A minority of patients may experience temporary improvement without treatment, but most of them relapse and develop chronic disease that progresses variably.

\section{Differential Diagnoses:}

\section{Primary sclerosing cholangitis}

Isolated IgG4-related sclerosing cholangitis may mimic primary sclerosing cholangitis as the latter can also present with elevated liver function enzymes. Primary sclerosing cholangitis typically affects younger patients, in the third to fourth decades of life, and is less often symptomatic than IgG4-related counterpart. Furthermore, primary sclerosing cholangitis is often associated with inflammatory bowel disease, with Crohn's disease and ulcerative colitis reportedly diagnosed in $70 \%$ and $87 \%$ of patients with the condition, respectively. Primary sclerosing cholangitis is characterized by multifocal short strictures with intervening biliary dilatation resulting in a beaded appearance on CT and MRI [2]. Periductal soft tissue is absent, unlike in IGg4-related disease, where it is characteristic [4].

\section{Systemic Vasculitis - Takayasu's and ANCA- associated}

Systemic vasculitis should be on the differential diagnosis for IgG4-related disease that involves vasculature [7]. Takayasu's arteritis is a large vessel vasculitis that often involves the thoracic and abdominal aorta, subclavian arteries, carotid arteries, pulmonary arteries, and large mesenteric arteries. It typically affects young to middle-aged women. Long smooth stenoses are classic on imaging. Various ANCAassociated vasculitides can affect medium and small vessels and 
are associated with elevated ANCA antibodies. Angiogram, CT or MRA may show stenosis or occlusion of affected vessels. Ultrasound may illustrate mural layering, reflecting inflammation. On MRI, vessel wall edema may appear as T2 hyperintense and mural inflammation may demonstrate restricted diffusion. PET may show metabolically active perivascular tissue. Both IgG4-related disease and systemic vasculitides can be associated with arterial dilatation or inflammatory aortic aneurysms.

\section{Cholangiocarcinoma}

When there is biliary involvement, cholangiocarcinoma may also be on the differential. Cholangiocarcinoma may present as a mass with irregular peripheral enhancement on CT or MRI [8]. Diffuse periductal thickening and dilated or irregular narrowing of ducts can be seen. Hallmark features on MRI include a T2 hyperintense mass with overlying capsular retraction and possible associated restricted diffusion [4]. Cholangiocarcinoma can encase vasculature and may demonstrate satellite nodules [8]. It is expected to be metabolically active on PET imaging. IgG-4 levels are normal.

\section{Hepatitis}

As IgG4-related disease can affect the liver, viral hepatitis is on the differential diagnosis when LFTs are elevated. Patients with viral hepatitis often exhibit hepatomegaly with heterogeneous contrast enhancement on cross-sectional imaging [9]. Periportal edema is common. Parenchymal edema appears as regions of low attenuation on CT, regions of high T2 signal on MRI, and hypoechogenicity on US. Parenchymal inflammation may demonstrate restricted diffusion. Biliary structuring is absent, distinguishing it from IgG4-related disease. Viral serology findings are also specific to this entity.

\section{TEACHING POINT}

IgG4-related autoimmune disease is a rare immune-mediated systemic condition characterized by focal or diffuse inflammation that can involve multiple organ systems in the form of autoimmune pancreatitis, sclerosing cholangitis, retroperitoneal fibrosis, vasculitis and prostatitis. IgG4-related disease generally has a good prognosis and a favorable response to steroid therapy, and timely diagnosis is thus paramount to avoid the chemoradiation or surgical excision that may be considered for other diseases

\section{REFERENCES}

1. Hedgire SS. McDermott S. Borczuk D. et al. The Spectrum of IgG4-Related Disease in the Abdomen and Pelvis. Am J Roentgenol. 2013 Jul; 201(1):14-22. 23789654.

2. Khoshpouri PP. Habibabadi RR. Hazhirkarzar B. et al. Imaging Features of Primary Sclerosing Cholangitis: From Diagnosis to Liver Transplant Follow-up RadioGraphics. 2019 Nov; 39(7):1938-64. 31626561.
3. Madhusudhan KS. Das P. Gunjan D. et al. IgG4-Related Sclerosing Cholangitis: A Clinical and Imaging Review. Am J Roentgenol. 2019 Dec; 213(6):1221-31. 31509439.

4. Martinez-de-Algeria A. Baleato-González S. GarcíaFigueriras R. et al. IgG4-related Disease from Head to Toe. RadioGraphics. 2015 Nov; 35(7):2007-25. 26473450.

5. Caiafa RO. Vinuesa AS. Izquierdo RS. et al. Retroperitoneal Fibrosis: Role of Imaging in Diagnosis and Follow-up. RadioGraphics. 2013 Mar; 33(5):535-52. 23479712.

6. Tang CSW. Sivarasan N. Griffin N. Abdominal manifestations of IgG4-related disease: a pictorial review. Insights Imaging. 2018 Aug; 9(4):437-48. 29696607.

7. Spira D. Kötter I. Ernemann U. et al. Imaging of Primary and Secondary Inflammatory Diseases Involving Large and Medium-Sized Vessels and Their Potential Mimics: A Multitechnique Approach. Am J Roentgenol. 2010 Mar; 194(3):848-56. 20173169.

8. Chung YE. Kim MJ. Park YN. et al. Varying Appearances of Cholangiocarcinoma: Radiologic-Pathologic Correlation. RadioGraphics. 2009 May; 29(3):683-700. 19448110.

9. Mortelé KJ. Segatto E. Ros PR. et al. The Infected Liver: Radiologic-Pathologic Correlation. RadioGraphics. 2004 Jul; 24(4):937-55. 15256619.

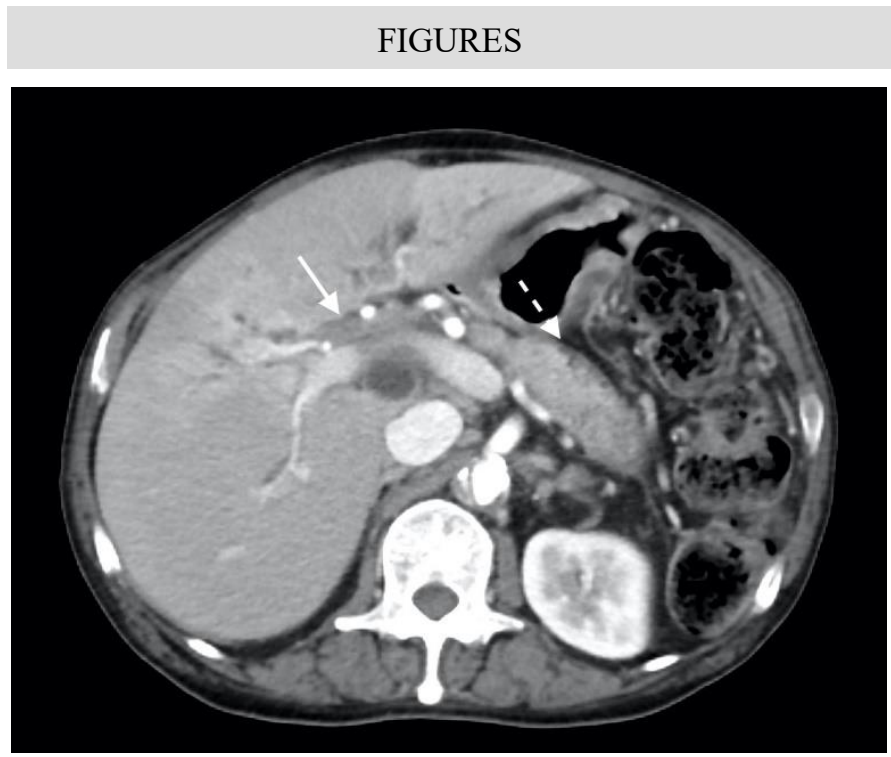

Figure 1: 78 year-old male with IgG4-related autoimmune disease.

Findings: Axial contrast-enhanced CT demonstrates enhancing soft tissue in the biliary hilum (solid arrow) and loss of pancreatic parenchymal lobulations with a peripancreatic soft tissue rind (dashed arrow).

Technique: Axial Multi-detector CT, Portal Venous phase (100 ml Omnipaque), mA 50-200; kV 120; 5.0 mm slice thickness. 


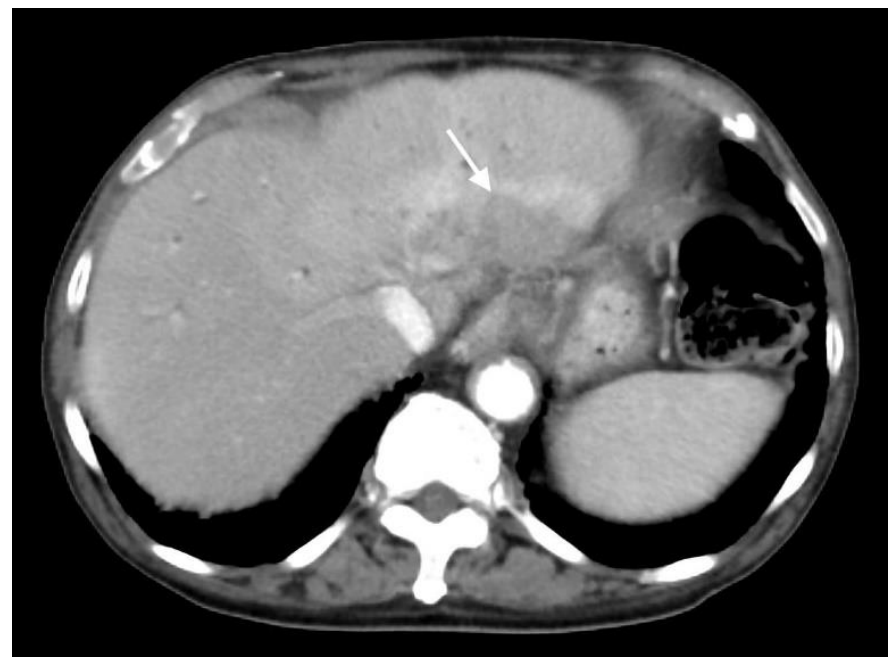

Figure 2: 78 year-old male with IgG4-related autoimmune disease.

Findings: Axial contrast-enhanced CT shows heterogenous hepatic parenchymal enhancement (arrow).

Technique: Axial Multi-detector CT, Portal Venous phase (100 $\mathrm{ml}$ Omnipaque), mA 50-200; kV 120; 5.0 mm slice thickness.

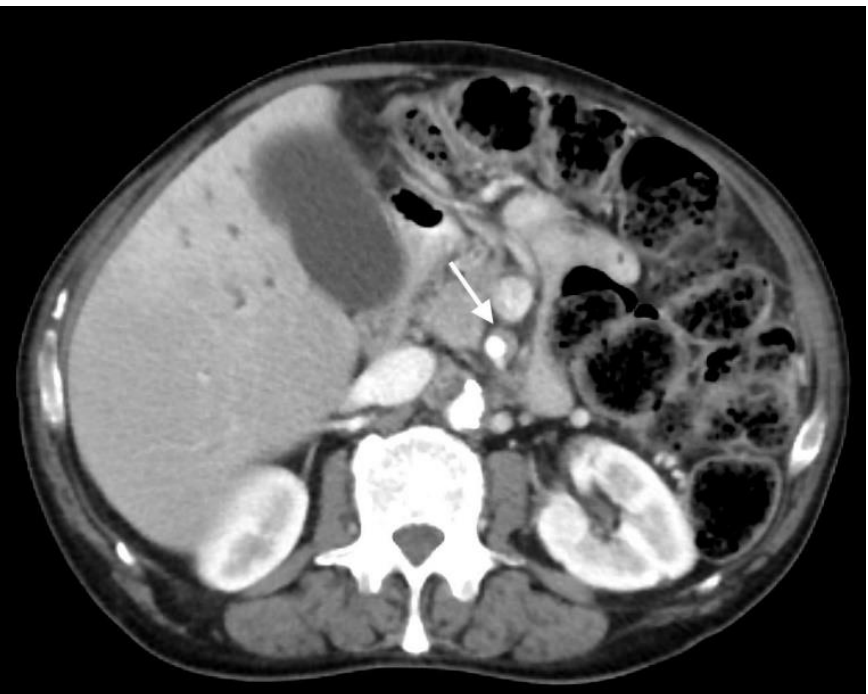

Figure 3: 78 year-old male with IgG4-related autoimmune disease.

Findings: Axial contrast-enhanced CT demonstrates soft tissue around the superior mesenteric artery (arrow).

Technique: Axial Multi-detector CT, Portal Venous phase (100 ml Omnipaque), mA 50-200; kV 120; 5.0 mm slice thickness.

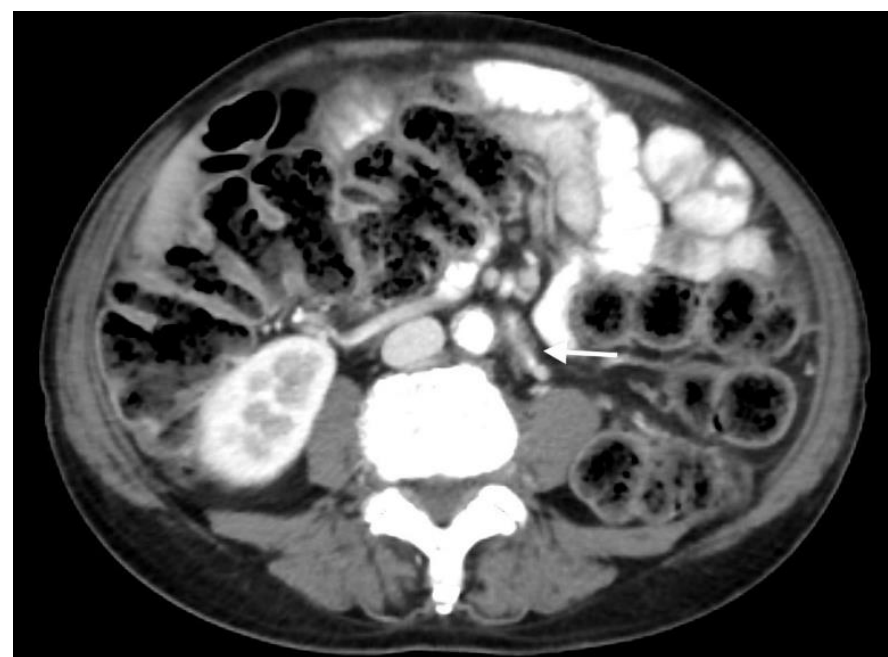

Figure 4: 78 year-old male with IgG4-related autoimmune disease.

Findings: Axial contrast-enhanced CT demonstrates soft tissue encasing the inferior mesenteric artery (arrow).

Technique: Axial Multi-detector CT, Portal Venous phase (100 ml Omnipaque), mA 50-200; kV 120; 5.0 mm slice thickness.

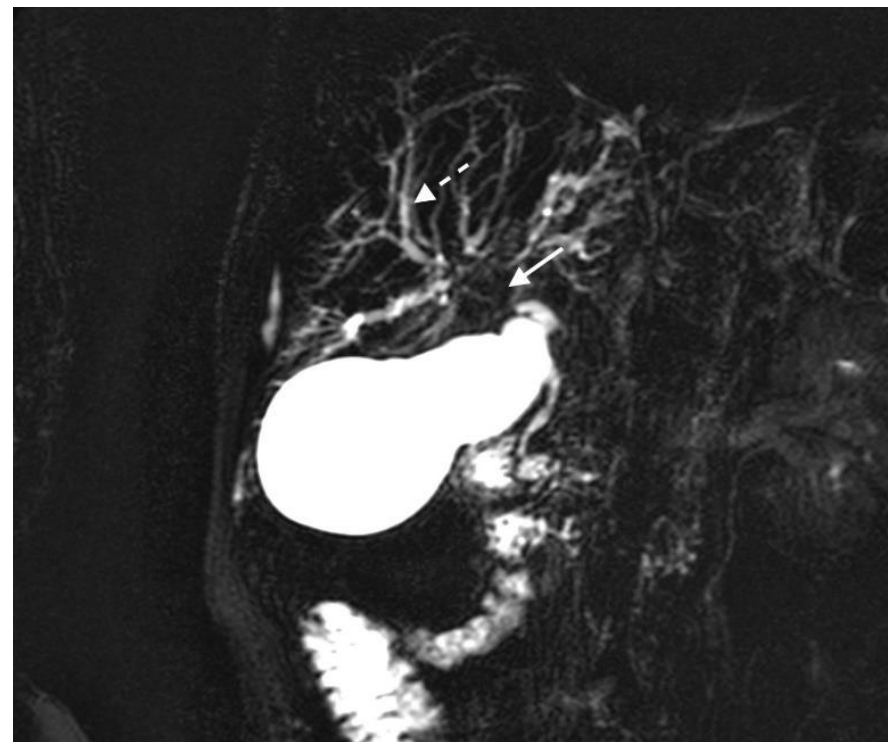

Figure 5: 78 year-old male with IgG4-related autoimmune disease.

Findings: Magnetic resonance cholangiopancreatography (MRCP) shows absent fluid signal within the proximal common bile duct and biliary hilum (solid arrow) consistent with a long segment stricture and intrahepatic biliary dilatation (dashed arrow).

Technique: Coronal MRCP MIP (1.5T, TR 300, TE 97.5, Slice spacing 367) 


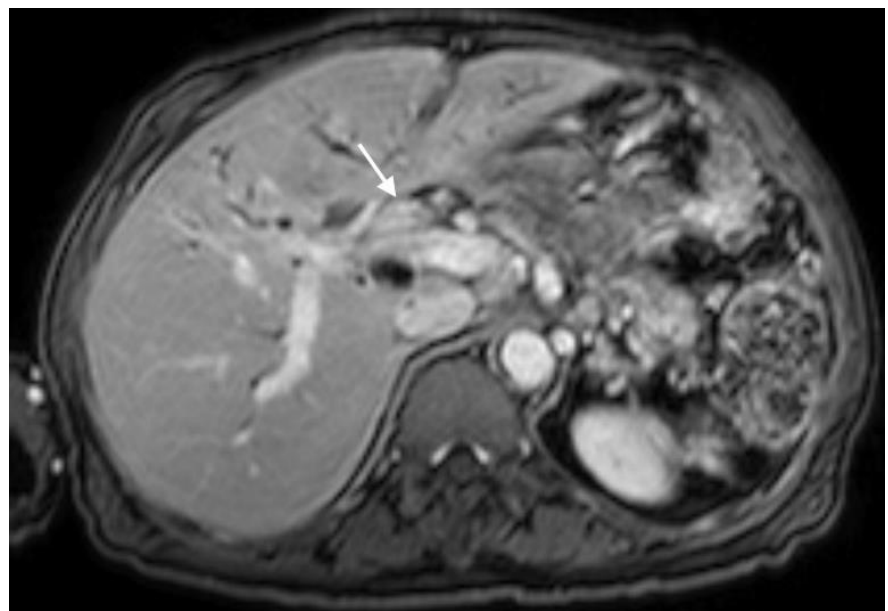

Figure 6: 78 year-old male with IgG4-related autoimmune disease.

Findings: Contrast enhanced MRI demonstrates enhancing stricture at the proximal CBD (arrow).

Technique: Axial T1-weighted fat saturation with intravenous contrast $(6.7 \mathrm{~mL}$ Gadavist). $1.5 \mathrm{~T}, \mathrm{TR}=5.86, \mathrm{TE}=0,2.5 \mathrm{~mm}$ slice thickness.

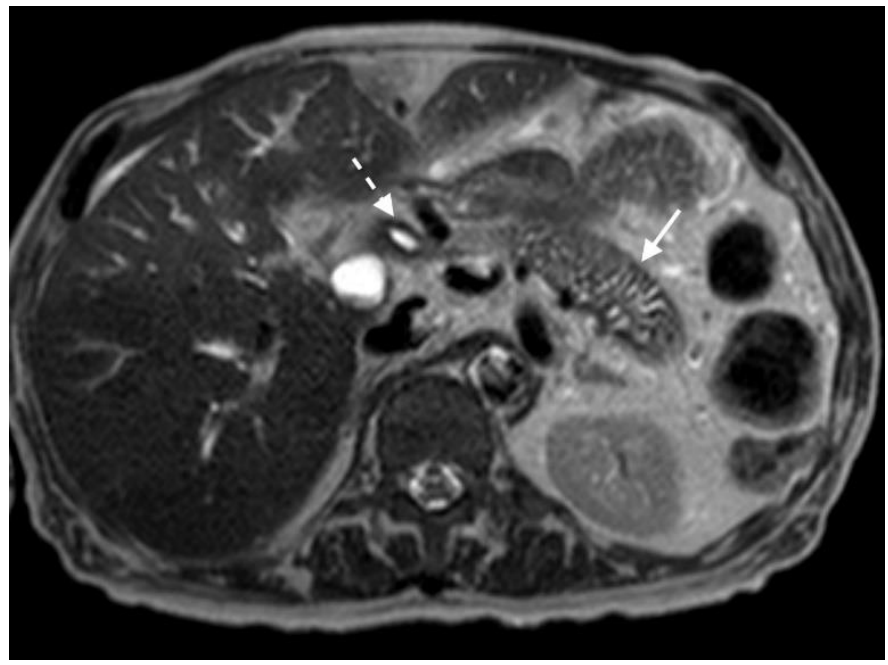

Figure 7: 78 year-old male with IgG4-related autoimmune disease.

Findings: T2-weighted MRI demonstrates loss of pancreatic parenchymal lobulations with peripheral soft tissue rind (solid arrow) best seen along the distal pancreatic body and tail and stricture at the proximal CBD (dashed arrow).

Technique: Axial T2-weighted. 1.5T, $\mathrm{TR}=1000, \mathrm{TE}=80,5$ mm slice thickness.

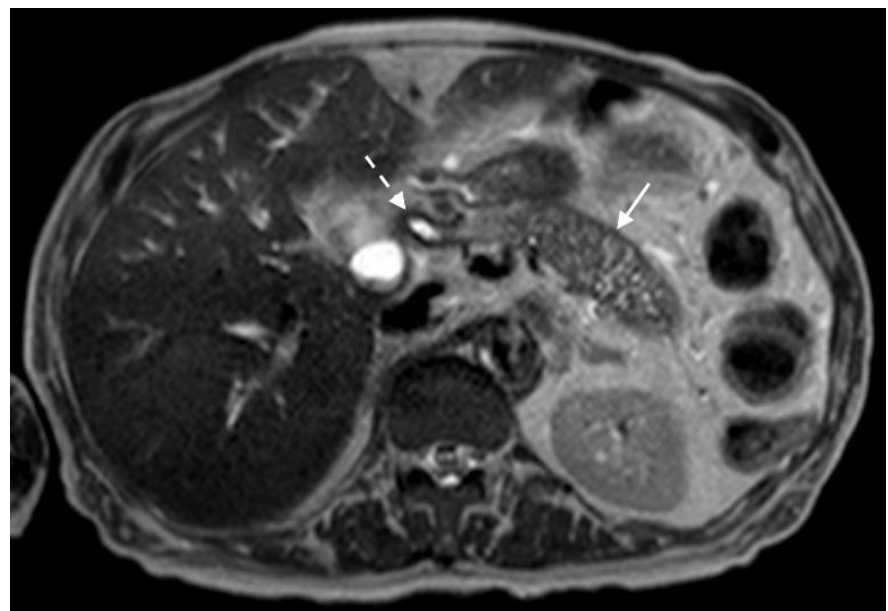

Figure 8: 78 year-old male with IgG4-related autoimmune disease.

Findings: T2-weighted MRI demonstrates loss of pancreatic parenchymal lobulations with peripheral soft tissue rind (solid arrow) seen throughout the pancreatic body and stricture at the proximal CBD (dashed arrow).

Technique: Axial T2-weighted. 1.5T, TR $=1000, \mathrm{TE}=80,5$ mm slice thickness.

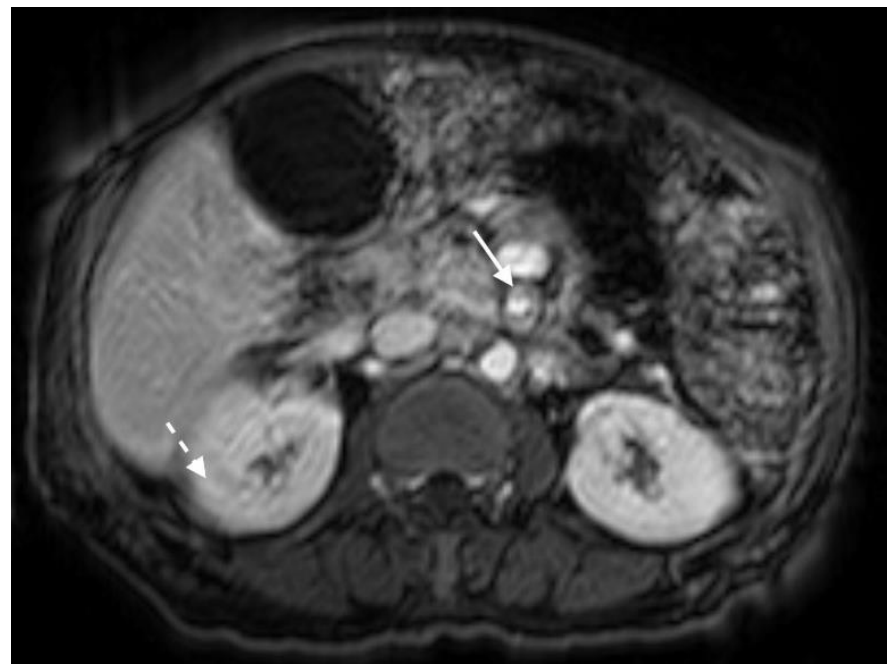

Figure 9: 78 year-old male with IgG4-related autoimmune disease.

Findings: Contrast enhanced MRI demonstrates enhancing soft tissue around the SMA (solid arrow). Also note lack of hypoenhancement in the renal kidneys (dashed arrow).

Technique: Axial T1-weighted fat saturation $(6.7 \mathrm{~mL}$ Gadavist). $1.5 \mathrm{~T}, \mathrm{TR}=5.86, \mathrm{TE}=0,2.5 \mathrm{~mm}$ slice thickness . 


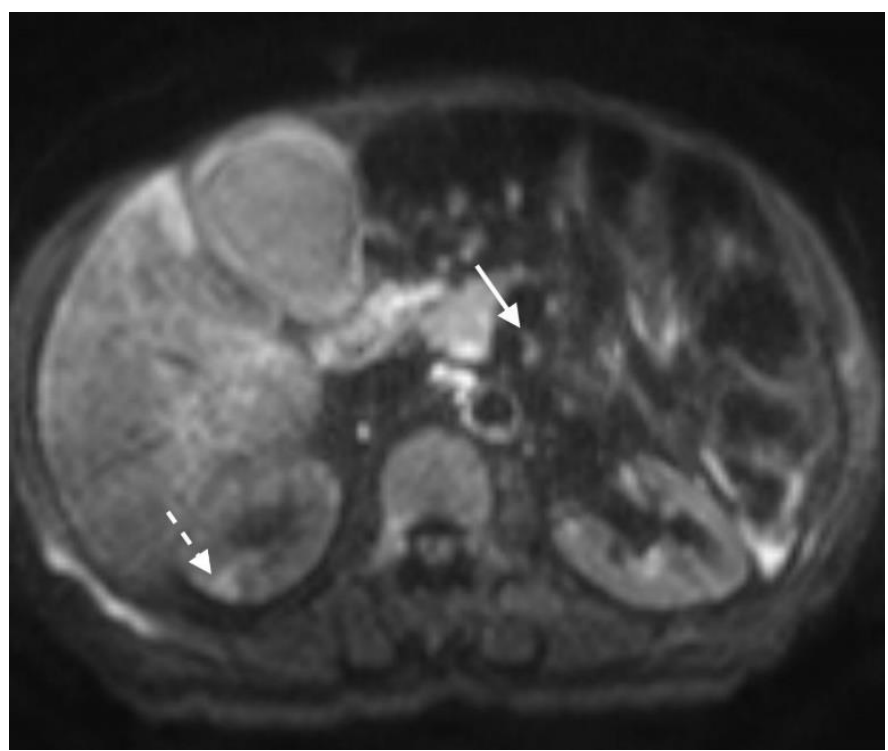

Figure 10: 78 year-old male with IgG4-related autoimmune disease.

Findings: DWI MRI demonstrates hyperintense soft tissue surrounding the SMA (solid arrow). Also note regions of hyperintensity throughout the renal parenchyma (dashed arrow).

Technique: Axial DWI- weighted (1.5T, TR 1372, TE 62.5, slice spacing 6.6)

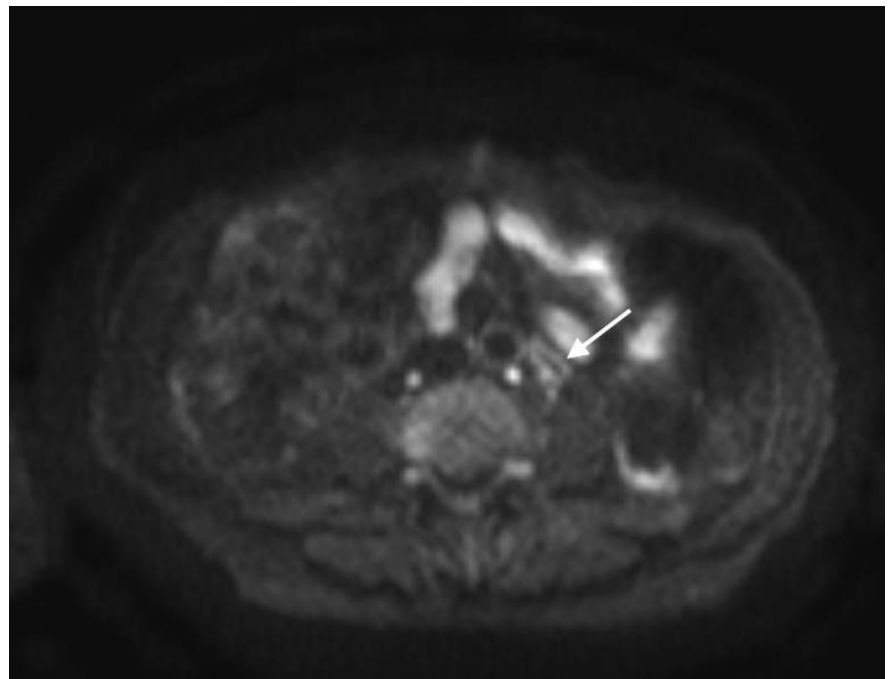

Figure 11: 78 year-old male with IgG4-related autoimmune disease.

Findings: DWI MRI demonstrates hyperintense soft tissue surrounding the IMA (arrow).

Technique: Axial DWI- weighted (1.5T, TR 1372, TE 62.5, slice spacing 6.6)

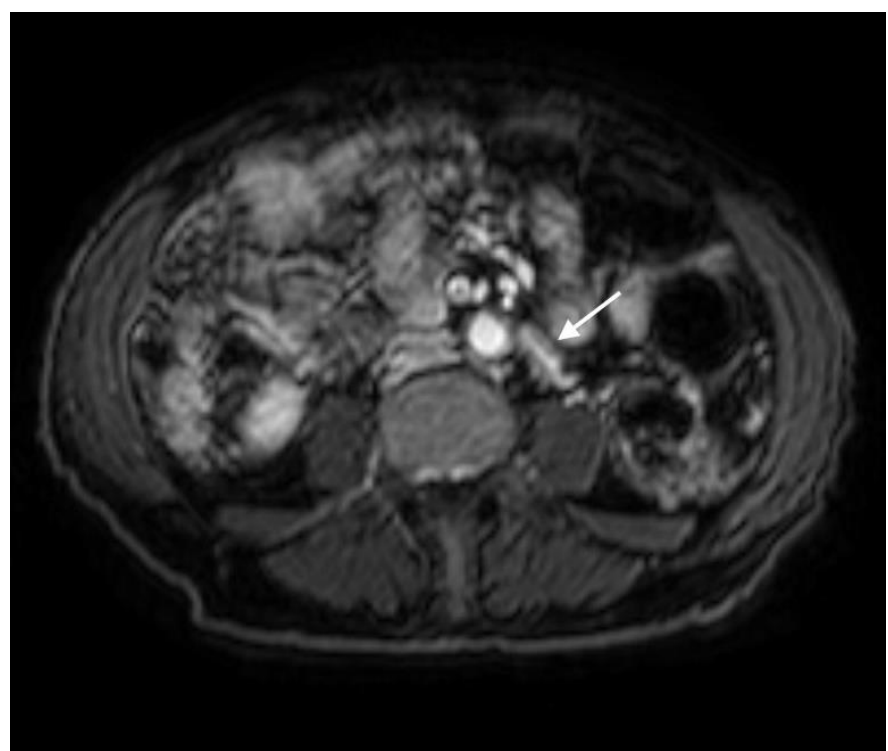

Figure 12: 78 year-old male with IgG4-related autoimmune disease.

Findings: Contrast enhanced MRI shows enhancing soft tissue surrounding the IMA (arrow).

Technique: Axial DWI- weighted (1.5T, TR 1372, TE 62.5, slice spacing 6.6) 


\begin{tabular}{|l|l|}
\hline Etiology & Autoimmune, IgG4-mediated \\
\hline Incidence & 2-11\% of those with chronic pancreatitis \\
\hline Gender ratio & M:F 4-7.5:1 \\
\hline Age Predilection & Mean age 59-68 y/o \\
\hline Risk factors & $\begin{array}{l}\text { Autoimmune pancreatitis, sclerosing mesenteritis, associated with few allergic diseases (sinusitis, } \\
\text { asthma). }\end{array}$ \\
\hline Treatment & Steroid therapy \\
\hline Prognosis & $\begin{array}{l}\text { Excellent with steroid therapy. Marked improvement in pancreatic function and morphology has } \\
\text { been seen within 4-6 weeks. }\end{array}$ \\
\hline Findings on imaging & $\begin{array}{l}\text { Autoimmune pancreatitis, sclerosing cholangitis, hepatopathy and inflammatory hepatic } \\
\text { pseudotumor, aortitis and retroperitoneal fibrosis, renal rounded or wedge-shaped parenchymal } \\
\text { lesions, perinephric soft tissue rind, or diffuse enlargement. }\end{array}$ \\
\hline
\end{tabular}

Table 1: Summary table of IgG4-Related Disease.

\begin{tabular}{|c|c|c|c|c|c|}
\hline & $\begin{array}{l}\text { Primary sclerosing } \\
\text { cholangitis }\end{array}$ & $\begin{array}{l}\text { Systemic vasculitis - } \\
\text { Takayasu's and ANCA- } \\
\text { associated }\end{array}$ & Cholangiocarcinoma & Hepatitis & $\begin{array}{l}\text { IgG4-related autoimmune } \\
\text { disease }\end{array}$ \\
\hline$\stackrel{x}{x}$ & - Not generally utilized & $\begin{array}{l}\text { - Angiogram may show } \\
\text { stenosis and occlusion }\end{array}$ & - Not generally utilized & $\begin{array}{l}\text { - Not generally } \\
\text { utilized }\end{array}$ & - Not generally utilized \\
\hline$\stackrel{\mathscr{s}}{\Omega}$ & $\begin{array}{l}\text { - Thickening bile duct } \\
\text { walls } \\
\text { - Biliary dilatation }\end{array}$ & $\begin{array}{l}\text { - Shows mural thickening } \\
\text { - Mural layering } \\
\text { reflecting inflammation }\end{array}$ & $\begin{array}{l}\text { - Can detect mass } \\
\text { - Biliary obstruction }\end{array}$ & $\begin{array}{l}\text { - Enlarged liver } \\
\text { - Diffuse decrease } \\
\text { parenchymal } \\
\text { echogenicity } \\
\text { - Increase } \\
\text { echogenicity portal } \\
\text { vein walls (“Starry } \\
\text { night" pattern) } \\
\text { - Can have normal } \\
\text { liver echogenicity }\end{array}$ & $\begin{array}{l}\text { - Biliary stricture and mural } \\
\text { thickening } \\
\text { - Biliary dilatation }\end{array}$ \\
\hline v & $\begin{array}{l}\text { - Thickening and } \\
\text { enhancement bile } \\
\text { duct wall } \\
\text { Focal, peripheral } \\
\text { intrahepatic biliary } \\
\text { dilatation }\end{array}$ & $\begin{array}{l}\text { - Mural thickening } \\
\text { - Mural enhancement } \\
\text { - Luminal narrowing }\end{array}$ & $\begin{array}{l}\text { - Mass with irregular } \\
\text { peripheral enhancement } \\
\text { - Diffuse periductal } \\
\text { thickening } \\
\text { - Abnormal dilated or } \\
\text { irregular narrowed duct }\end{array}$ & $\begin{array}{l}\text { - Hepatomegaly } \\
\text { - Periportal edema } \\
\text { - Heterogenous } \\
\text { enhancement } \\
\text { - Regions low } \\
\text { attenuation }\end{array}$ & $\begin{array}{l}\text { - Biliary dilatation and mural } \\
\text { thickening } \\
\text { - Autoimmune pancreatitis }\end{array}$ \\
\hline$\underline{z}$ & $\begin{array}{l}\text { - T1: Normal signal } \\
\text { intensity } \\
\text { - T2: Multifocal short } \\
\text { strictures with } \\
\text { intervening biliary } \\
\text { dilatation resulting in } \\
\text { a beaded appearance } \\
\text { - DWI: Biliary stricture } \\
\text { with restricted } \\
\text { diffusion }\end{array}$ & $\begin{array}{l}\text { - T1: Normal signal } \\
\text { intensity } \\
\text { - T2: Vessel wall edema } \\
\text { intense } \\
\text { - DWI: Mural } \\
\text { inflammation with } \\
\text { restricted diffusion }\end{array}$ & $\begin{array}{l}\text { - T1: Normal or low } \\
\text { intensity } \\
\text { - T2: Hyperintense mass } \\
\text { - Overlying capsular } \\
\text { retraction } \\
\text { - Strictures irregular } \\
\text { margins, asymmetric } \\
\text { arrowing } \\
\text { - DWI: Mass with } \\
\text { restricted diffusion }\end{array}$ & $\begin{array}{l}\text { - T1: Normal or } \\
\text { decreased signal } \\
\text { intensity } \\
\text { - T2: Periportal edema } \\
\text { high signal } \\
\text { - Parenchyma edema } \\
\text { high signal intensity } \\
\text { - Absent biliary } \\
\text { stricture } \\
\text { - DWI: Parenchymal } \\
\text { inflammation with } \\
\text { restricted diffusion }\end{array}$ & $\begin{array}{l}\text { - T1: Normal or decreased } \\
\text { signal intensity pancreas } \\
\text { - Normal or decreased signal } \\
\text { intensity hepatic } \\
\text { inflammation } \\
\text { - T2: Biliary involvement as } \\
\text { solitary structure with } \\
\text { periportal soft tissue } \\
\text { - Often with autoimmune } \\
\text { pancreatitis } \\
\text { - Focal hepatic inflammation } \\
\text { - DWI: Biliary stricture wall } \\
\text { with restricted diffusion }\end{array}$ \\
\hline 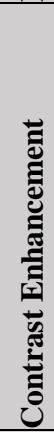 & $\begin{array}{l}\text { - Absent periductal soft } \\
\text { tissue }\end{array}$ & $\begin{array}{l}\text { - Mural enhancement } \\
\text { - Involves aorta } \\
\text { frequently }\end{array}$ & $\begin{array}{l}\text { - Delayed centripetal } \\
\text { enhancement } \\
\text { - Overlying capsular } \\
\text { retraction } \\
\text { - Vascular encasement } \\
\text { - Satellite nodules } \\
\text { - Less well-defined, often } \\
\text { branching spiculated } \\
\text { lesion }\end{array}$ & $\begin{array}{l}\text { - Heterogenous } \\
\text { contrast } \\
\text { enhancement }\end{array}$ & $\begin{array}{l}\text { - Vasculitis involving aorta } \\
\text { branch vessels }\end{array}$ \\
\hline$\frac{1}{2}$ & - Not generally used & $\begin{array}{l}\text { Metabolically active } \\
\text { perivascular tissue }\end{array}$ & $\begin{array}{l}\text { - Metabolically active } \\
\text { mass }\end{array}$ & - Not generally used & - Not generally used \\
\hline
\end{tabular}

Table 2: Differential diagnosis table for IgG4-Related Disease. 


\section{ABBREVIATIONS}

AIP $=$ Autoimmune pancreatitis

ANCA = Antineutrophilic cytoplasmic antibodies

$\mathrm{CBD}=$ Common bile duct

$\mathrm{CT}=$ Computed tomography

LFT's = Liver function tests

MRCP = Magnetic resonance cholangiopancreatography

MRI = Magnetic resonance imaging

\section{KEYWORDS}

IgG4-related disease; autoimmune; abdomen; MRI; CT

\section{Online access}

This publication is online available at:

www.radiologycases.com/index.php/radiologycases/article/view/4266

\section{Peer discussion}

Discuss this manuscript in our protected discussion forum at: www.radiolopolis.com/forums/JRCR

\section{Interactivity}

This publication is available as an interactive article with scroll, window/level, magnify and more features.

Available online at www.RadiologyCases.com

\section{Published by EduRad}

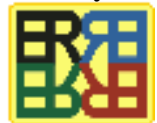

www.EduRad.org 